\title{
Salvage chemotherapy in metastatic colorectal cancer with the combination of capecitabine and mitomycin $\mathrm{C}$
}

\author{
A. L. ZYGULSKA ${ }^{1, *}$, K. KRZEMIENIECKI ${ }^{2}$ \\ ${ }^{1}$ Department of Clinical Oncology, Krakow University Hospital, Sniadeckich St. 10, 31-531 Krakow, Poland; ${ }^{2}$ Department of Oncology, Jagiellon- \\ ian University, Sniadeckich St. 10, 31-531 Krakow, Poland
}

${ }^{*}$ Correspondence: zygulska@poczta.onet.pl

Received September 1 , 2014 / Accepted May 6, 2015

\begin{abstract}
A significant proportion of heavily pretreated patients with metastatic colorectal cancer maintain good performance status (PS) and are eligible for further systemic treatment. Mitomycin C (MMC) combined with capecitabine can be considered as salvage treatment in this group of patients. To evaluate the efficacy and toxicity of mitomycin $\mathrm{C}$ and capecitabine as at least third-line systemic therapy (after failure of 5Fu, irinotecan, oxaliplatin-based chemotherapy regimens and targeted therapies) in patients with metastatic colorectal cancer. A total of 31 patients with a median age of 55.2 years with metastatic colorectal cancer received salvage chemotherapy at the Oncological Department of University Hospital in Krakow, Poland, between July 2011 and July 2014. Chemotherapy consisted of intravenous MMC $6 \mathrm{mg} / \mathrm{m} 2$ on day 1 and oral capecitabine $1000 \mathrm{mg} / \mathrm{m} 2$ twice daily on days 1-14 followed by a 7-day treatment-free interval. Each cycle was repeated every 3 weeks unless there was evidence of disease progression or unacceptable toxicity. All the31 patients were evaluable for response and toxicity. A total of 113 cycles were administered. Five of the 31 (16.1\%) patients had stable disease after three cycles of chemotherapy, 24 (77.4\%) patients progressed and 1 (3.2\%) patient is still undergoing treatment. One patient (3.2\%) died due to cardiac infarct 5 days after starting treatment. Median progression free survival (PFS) was 2.5 months. Median overall survival (OS) was 4.9 months. Toxicity was mild and easily manageable. Mitomycin $\mathrm{C}$ and capecitabine can be considered as salvage therapy in heavily pretreated patients with metastatic colorectal cancer and with good performance status. Toxicity of these drugs combination is moderate and easily manageable.
\end{abstract}

Key words: mitomycin C, capecitabine, metastatic colorectal cancer

Mitomycin $\mathrm{C}$ is an antitumor antibiotic with modest single-agent activity against metastatic colorectal cancer. Mitomycin C induces up-regulation of intratumoral thymidine phosphorylase - the pivotal enzyme for the convertion of capecitabine to $5 \mathrm{Fu}$ [1]. This mechanism can possibly be responsible for clinically significant synergy with capecitabine. A significant proportion of heavily pretreated patients with metastatic colorectal cancer present good performance status and are eligible for further systemic treatment. MMC and capecitabine can be considered as a salvage chemotherapy in this group of patients. The aim of this prospective study is to evaluate the efficacy and tolerability of MMC combined with capecitabine in patients with metastatic colorectal cancer pretreated at least three lines of systemic treatment.

\section{Patients and methods}

Thirty one patients (19 males and 12 females) with metastatic colorectal cancer were treated at the Oncological Department of University Hospital in Krakow, Poland, between July 2011 and July 2014. Patients with histologically confirmed metastatic colorectal cancer were enrolled in this study. All patients signed informed consent. Patients were pretreated with a minimum of three lines systemic treatment with progression, after failure of $5 \mathrm{Fu}$, irinotecan, oxaliplatin-based chemotherapy regimens and targeted therapies such as: panitumumab, cetuximab, bevacizumab.

The vast majority of patients had the ECOG (Eastern Cooperative Oncology Group) performance status of 0 or 1 . Overall 


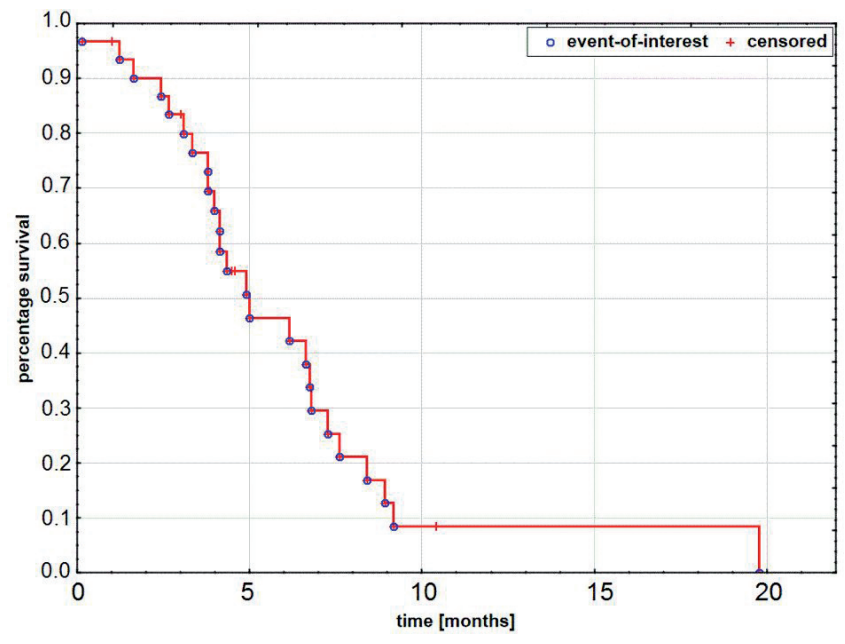

Figure 1. The Kaplan-Meier survival curve - the overall survival.

survivall was a minimum of 3 months. Patients had adequate bone marrow, renal and hepatic functions.

Table 1. Patient characteristics.

\begin{tabular}{|c|c|}
\hline patient characteristics & number $(\mathrm{n}=31)$ \\
\hline sex & $\mathrm{M}: \mathrm{F}=19(61.3 \%): 12(38.7 \%)$ \\
\hline median age (range) & 55.2 years ( $34-74$ years) \\
\hline primary site & $\begin{array}{l}\text { colon -18 }(58.1 \%) \\
\text { rectum -13 }(41.9 \%)\end{array}$ \\
\hline sites of metastases & $\begin{array}{l}\text { liver - } 15(48.5 \%) \\
\text { liver and lungs - } 10(32.3 \%) \\
\text { peritoneum and local recurrence - } 2(6.4 \%) \\
\text { liver and bones - } 1(3.2 \%) \\
\text { liver and local recurrence }-1(3.2 \%) \\
\text { liver, lungs and lymph nodes - } 1(3.2 \%) \\
\text { liver and lymph nodes - } 1(3.2 \%)\end{array}$ \\
\hline performance status & $\begin{array}{l}\text { PS } 0-10(32.3 \%) \\
\text { PS } 1-17(54.8 \%) \\
\text { PS } 2-4(12.9 \%) \\
\end{array}$ \\
\hline previous surgical treatment & $\begin{array}{l}\text { YES - } 29(93.5 \%) \\
\text { NO }-2(6.5 \%)\end{array}$ \\
\hline previous radiotherapy & $\begin{array}{l}\text { YES - } 4(12.9 \%) \\
\text { NO- } 27(87.1 \%)\end{array}$ \\
\hline line of systemic treatment & $\begin{array}{l}\text { third line - } 13(41.9 \%) \\
\text { fourth line - } 12(38.7 \%) \\
\text { fifth line - } 6(19.4 \%)\end{array}$ \\
\hline $\begin{array}{l}\text { number of cycles } \\
\text { (range: } 1-13 \text { cycles) }\end{array}$ & $\begin{array}{l}1 \text { cycle }-5 \text { patients }(16.2 \%) \\
2 \text { cycles }-5 \text { patients }(16.2 \%) \\
3 \text { cycles }-7 \text { patients }(22.6 \%) \\
4 \text { cycles }-9 \text { patients }(29.0 \%) \\
5 \text { cycles }-1 \text { patient }(3.2 \%) \\
6 \text { cycles }-1 \text { patient }(3.2 \%) \\
8 \text { cycles }-1 \text { patient }(3.2 \%) \\
9 \text { cycles }-1 \text { patient }(3.2 \%) \\
13 \text { cycles - } 1 \text { patient }(3.2 \%)\end{array}$ \\
\hline
\end{tabular}

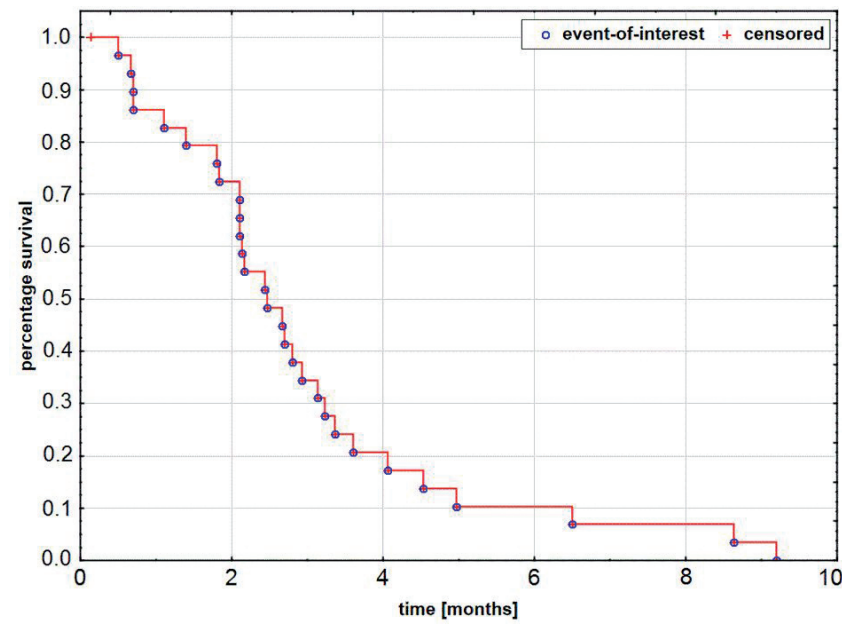

Figure 2. The Kaplan-Meier survival curve - the progression-free survival.

Adverse events were evaluated every three weeks according to the National Cancer Institute Common Toxicity Criteria (NCI-CTC, version 2.1). Treatment efficacy was evaluated according to the WHO criteria. Overall survival was calculated from the start of chemotherapy to the patient's death. Progression free survival was defined as time from the start of chemotherapy to the patient's deterioration or progression, evaluated on the basis of the abdomen and chest CT scans.

Chemotherapy regimen consisted of intravenous mitomycin C $6 \mathrm{mg} / \mathrm{m} 2$ on day 1 and oral capecitabine $1000 \mathrm{mg} / \mathrm{m} 2$ twice daily on days 1-14 followed by a 7-day rest treatment-free interval. Each cycle was repeated every 3 weeks till disease progression or unacceptable toxicity.

Patient characteristics are shown in Table 1.

Kaplan-Meier survival analysis was performed to assess overall survival and progression free survival. All survival times were calculated from the date of the first treatment. All calculations were performed using STATISTCA version 10 .

\section{Results}

All 31 patients were evaluable for response and toxicity. A total of 113 cycles were administered (median 3.6; range:113 cycles). Five of the $31(16,1 \%)$ patients had stable disease after three cycles of chemotherapy. Finally, 28 patients $(90.3 \%)$ progressed (18/28 - radiologically confirmed progression - and 10/28 - deterioration in performance status within chemotherapy). One patient died due to cardiac infarct 5 days after starting treatment. The autopsy was not performed. The relation between the death cause and chemotherapy was probable but not certain that patient had cardiologic history. Reasons for treatment completion are shown in Table 2. One patient $(3.2 \%)$ is still undergoing treatment. Twenty-five of the 31 patients $(80.6 \%)$ died. One patient $(3.2 \%)$ was lost to follow-up. The patient was 8.4 months in follow-up. 
Five patients (16.1\%) are still alive. In the group of all patients treated at the Department of Clinical Oncology mean observation time was $5.3 \pm 3.7$ months. Overall survival (OS, median, the survival time at which the cumulative survival function is equal to 0.5 calculated from Kaplan-Meier curve) for this group of patients was 4.9 months (the first quartile 3.5 months, the third quartile 7.3 months). Overall survival after treatment is shown in Figure 1. The mean time to progression was $2.9 \pm 2.2$ months. Progression-free survival (PFS) for this group of patients was 2.5 months (the first quartile 1.8 months, the third quartile 3.3 months). PFS after the treatment is shown in Figure 2. Toxicity was mild and easily manageable. Toxicity (G3) included thrombocytopenia 6.5\%, diarrhea $3.2 \%$ and fatigue $3.2 \%$. The whole spectrum of toxicity is shown in Table 3.

\section{Disscusion}

Mitomycin C is an old generation of anticancer drug that acts synergistically with capecitabine and irinotecan. It has been used in combination with modern compounds in various settings of metastatic colorectal cancer. The phase II study of capecitabine and mitomycin $\mathrm{C}$ was evaluated as first-line treatment in patients with advanced colorectal cancer. The overall response rate was $38 \%$. One third of the patients achieved stable disease for over 12 weeks [2]. Mitomycin C combinations are less efficacious than those of modern drugs in first-line treatment of colorectal cancer according to available data from the last forty years (Corchane database, PubMed, etc.) [3].

There were studies evaluating the efficacy and safety of continuous infusion of single -agent mitomycin $\mathrm{C}$ in patients with metastatic colorectal cancer progression after first-, second- or further line 5-fluorouracil-based chemotherapy. The median survival time ranged from 3.6 to 4.7 months [ 4 , 5]. Six month survival rate was $36 \%$ [4]. Continuous infusion of mitomycin $\mathrm{C}$ had good toxicity profile, but no satisfactory activity $[4,5,6]$.

The efficacy and safety of mitomycin $\mathrm{C}$ in combination with oral uracil/tegafur (UFT) and leucovorin were estimated as third-line treatment for patients with metastatic colorectal cancer. All patients had failed prior treatment with fluoropyrimidine, irinotecan, oxaliplatin and targeted therapies. The median time to progression ranged from 2.5 months to 5 months and median overall survival ranged from 6 months to 7.5 months $[7,8,9]$. The combination mitomycin $\mathrm{C}$ with UFT was an efficacious therapeutic option in about $30 \%$ heavily pretreated colorectal cancer patients $[7,9]$. Tolerance of the regimen was good [7, 8, 9]. In Alkis et al. study, mitomycin $\mathrm{C}$ in combination with fluoropyrimidines (oral UFT or infusional 5-Fu by de Gramont regimen) as third or fourth line in metastatic colorectal cancer patients resulted in 6 months progression free survival and in 9 months overall survival. Median progression free survival was 3 months in oral UFT group and 7 months in infusional 5Fu group. Median overal survivall was 7 months and 12 months, respectively [10].
The median time to treatment failure was 1.7 months and median survival was only 4.5 months in the largest published study of unselected refractory metastatic colorectal patients treated with mitomycin $\mathrm{C}$ alone or with capecitabine. Survival was comparable to that expected for the best supportive care. Generally, the results were disappointing [11]. As opposed to Ferrarotto's study, promising results in patients previously treated with at least one chemotherapy regimen were reported in a study from Croatia. The objective response rate was $15.2 \%$. Median failure-free survival was 5.4 months. The median time to tumor progression was 4.5 months, while median overall survival was13 months [12]. Similarly, in Chong et al. study, mitomycin $\mathrm{C}$ and capecitabine had comparable response rate $(15.2 \%)$ to monotherapy cetuximab in patients pretreated with $5 \mathrm{Fu}$ followed by irinotecan. Capecitabine and mitomycin $\mathrm{C}$ may be alternative if targeted therapies are contraindicated [13]. In other published series [14.15], the median time to progression ranged between 2 and 3 months while overall survival ranged between $6-6.8$ months were reported. According to the literature data, clinical benefit, defined as stable disease, partial and minor remission, was observed in 23\% to $48.5 \%$ of the patients treated with mitomycin $\mathrm{C}$ and capecitabine $[14,15,16,17]$.

The above data are related to the Caucasian patients. Only one study evaluating the efficacy and toxicity of Asian patients treated with mitomycin $\mathrm{C}$ and capecitabine has been published so far. Mitomycin $\mathrm{C}$ and capecitabine were given as third line systemic treatment. Overall response was in $33.3 \%$ of the patients. Median overall survival was 6.8 months. Tolerance of this regimen was good [18]. Kang et al. presented results of study regarding Asian patients treated with mitomycin $\mathrm{C}$ in combination with $5 \mathrm{Fu}$ as third line of systemic treatment. Stable disease was observed in $41.3 \%$. Median progressionfree survival was 10 weeks and median overall survival was 38 weeks. Toxicity profile was moderate [19].

Toxicity was moderate and generally acceptable in this group of patients. Hematological toxicity G3 occurred in 2

Table 2. Reason of the treatment completion

\begin{tabular}{lc}
\hline Reason & number $(\mathrm{n}=29)$ \\
\hline radiologically confirmed progression & $18(60 \%)$ \\
deterioration of performance status & $10(36.7 \%)$ \\
cardiac infarct & $1(3.3 \%)$ \\
\hline
\end{tabular}

Table 3. Toxicity of capecitabine and mitomycin $\mathrm{C}$ regimen.

\begin{tabular}{lcc}
\hline toxicity & number & all the grades \\
\hline palmar-plantar erythema & $2(6.5 \%)$ & $\mathrm{G} 1 / \mathrm{G} 2$ \\
nausea & $1(3.2 \%)$ & $\mathrm{G} 1$ \\
diarrhae & $1(3.2 \%)$ & $\mathrm{G} 3$ \\
thrombocytopenia & $2(6.5 \%)$ & $\mathrm{G} 3$ \\
fatigue & $1(3.2 \%)$ & $\mathrm{G} 3$ \\
\hline
\end{tabular}


Table 4. Combination of mitomycin $\mathrm{C}$ and capecitabine in the patients with metastatic colorectal cancer.

\begin{tabular}{|c|c|c|c|c|c|}
\hline author/year of publication & number of subjects & line of treatment & overall response [\%] & median PFS [months] & median OS [months] \\
\hline Rao S/ 2004 & 92 & I & 38 & 7.1 & 14.3 \\
\hline Chong G/2005 & 36 & III & 15.2 & 5.4 & 9.3 \\
\hline Lim DH/2005 & 21 & III & 33.3 & 2.6 & 6.8 \\
\hline Rimassa L/ 2006 & 28 & III & 47 & 2.0 & 6.0 \\
\hline Scartozzi M/ 2006 & 61 & III & 48 & 3.0 & 6.0 \\
\hline Vdorljak E/ 2008 & 36 & II, III or IV & 55.6 & 4.5 & 13.0 \\
\hline Ferarotto/2012 & $109^{*}$ & $\begin{array}{l}\text { II- } 11 \%, \text { III- } 38 \% \text {, } \\
\text { IV and further- } 51 \%\end{array}$ & - & 1.7 & 4.5 \\
\hline Saif MW/2013 & 15 & IV and further & 50 & - & - \\
\hline
\end{tabular}

* part of the patients received mitomycin $\mathrm{C}$ as a single agent

patients only. Non-hematological toxicity was described in 2 patients. According to other studies the regimen was also very well tolerated without significant hematological toxicity [14, 16]. Rarely were single cases of hematological toxicity G3 and G4 observed $[2,11,13,15,17,19]$. Therefore, the regimen may be an attractive option for patients with cumulative toxicities after previous systemic treatment [13].

In summary, overall survival lasting 4.9 months is disappointing, but other anticancer drugs such as gemcitabine or capecitabine have also very limited or hardly any efficacy in patients pretreated with $5 \mathrm{Fu}$, oxaliplatin and irinotecan [20]. It is important to emphasise that one fifth of the patients enrolled in this study had previously four lines osystemic treatment. Fifty percent of the patients had multiple sites of metastases. Patients may continue systemic treatment due to their good performance status and organ function reserves. This prospective study demonstrated a modest activity of mitomycin $\mathrm{C}$ and capecitabine in heavily pretreated patients with acceptable safety profile and low cost. Our results are consistent with the published data, especially with MIXE (mitomycin C-capecitabine) [16]. The significance and strength of this study lies in the fact that the regiment of mitomycin $\mathrm{C}$ and capecitabine can be an acceptable alternative for the best supportive care in the selected Caucasian and Asian patients with metastatic colorectal cancer. List of published studies with capecitabine and mitomycin $\mathrm{C}$ in colorectal cancer patients is shown in Table 4.

\section{Conclusions}

1. Mitomycin $\mathrm{C}$ and capecitabine can be considered as a salvage therapy in heavily pretreated patients with metastatic colorectal cancer and with good performance status. 2 . Toxicity of these drugs combination is moderate and easily manageable.

\section{References}

[1] SAWADA N, ISHIKAWA T, FUKASE Y, NISHIDA M, YOSHIKUBO T et al. Induction of thymidine phosphorylase activity and enhancement of capcitabine efficacy by taxol/ taxotere in human cancer xenografts. Clin Cancer Res 1998; 4: 1013-9.

[2] RAO S, CUNNINGHAM D, PRICE T, HILL ME, ROSS PJ et al. Phase II study of capecitabine and mitomycin C as firstline treatment in patients with advanced colorectal cancer. Br J Cancer 2004; 91: 839-843. http://dx.doi.org/10.1038/ sj.bjc. 6602039

[3] DIMOU A, SYRIGOS KN, SAIF MW. Is there a role of mitomycin $\mathrm{C}$ in metastatic colorectal cancer? Expert Opin Investiv Drugs 2010; 19: 723-35. http://dx.doi.org/10.1517/ $\underline{13543784.2010 .485191}$

[4] HARTMANN JT, HSTRICK A, DAIKELER T, KOLLMANNSBERGER C, MULLER C et al. Phase II study of continuous $120 \mathrm{~h}$ infusion of mitomycin $\mathrm{C}$ as salvage chemotherapy in patients with progressive or rapidly recurrent colorectal cancer. Anticancer Drugs 1998; 9: 427-31. http:// dx.doi.org/10.1097/00001813-199806000-00009

[5] HARTMANN JT, KANZ L, BOKEMEYER C. Phase II study of continuous 120-hour- infusion of mitomycin $\mathrm{C}$ as salvage chemotherapy in patients with progressive or rapidly recurrent gastrointestinal adenocarcinoma. Anticancer Res 2000; 20: $1177-82$.

[6] ANDRSON N, LOKICH J, MOORE C, BERN M, COCO F. A dose-escalation phase II clinical trial of infusional mitomycin $\mathrm{C}$ for 7 days in patients with advanced measurable colorectal cancer refractory or resistant to 5-fluorouracil. Cancer Invest 1999; 17: 586-93. http://dx.doi. org/10.3109/07357909909032844

[7] FRANCOISE E, SMITH D, DAHAN L, MICHEL C, PERRIER $\mathrm{H}$ et al. Uracil- tegafur/leucovorin and mitomycin $\mathrm{C}$ salvage therapy in patients with advanced colorectal cancer: a phase II study. J Chemother 2012; 24: 207-11. http://dx.doi. org/10.1179/1973947812Y.0000000021

[8] MIHALAKI V, GENNATAS S, GENNATAS C. Mitomycin $\mathrm{C}$ and UFT/leucovorin as salvage treatment in patients with advanced colorectal cancer. J BUON 2010; 15: 270-3.

[9] VORMITTAG L, KORNEK GV, GRUHSMANN B, LENAUER A, FOGER A et al. UFT/leucovorin and mitomycin $\mathrm{C}$ as salvage treatment in patients with advanced colorectal cancer - a retrospective analysis. Anticancer 
Drugs 2007; 18: 709-12. http://dx.doi.org/10.1097/ CAD.0b013e3280761a9d

[10] ALKIS N, DEMIRCI V, BENEKLI M, YILMAZ U, ISIKDOGEN A et al. A systematic review of salvage therapy to patients with metastatic colorectal cancer previously treated with fluorouracil, oxaliplatin and irinotecan $+/$ - targeted therapy. J BUON 2011; 16: 80-3.

[11] FERRAROTTO R, MACHADO K, MAK MP, SHAH N, TAKAHASHI TK et al. Multicenter, multinational analysis of mitomycin $\mathrm{C}$ in refractory metastatic colorectal cancer. Eur J Cancer 2012, 48: 820-6. http://dx.doi.org/10.1016/j. ejca.2012.01.008

[12] VDORLJAK E, OMRCEN T, BOBAN M, HREPIC D. Capecitabine and mitomycin- $\mathrm{C}$ in the therapy of pretreated patients with metastatic colorectal cancer: single center retrospective study with 36 patients. J BUON 2008; 13: 513-8.

[13] CHONG G, DICKSON JLB, CUNNINGHAM D, NORMAN $\mathrm{AR}, \mathrm{RAO} S$ et al. Capecitabine and mitomycin $\mathrm{C}$ as third-line therapy for patients with metastatic colorectal cancer resistant to fluorouracil and irinotecan. Br J Cancer 2005; 93: 510-4. http://dx.doi.org/10.1038/sj.bjc.6602733

[14] RIMASSA L, GULLO G, CARNAGHI C, ABBADESSA G, ZURADELLI L et al. Chemotherapy with mitomycin $C$ and capecitabine in patients with advanced colorectal cancer pretreated with irinotecan and oxaliplatin. Tumori 2006; 92: 285-9.

[15] SCARTOZZI M, FALCONE A, FUCCI F, BRACONI C, PIERANTONI $\mathrm{C}$ et al. Capecitabine and mitomycin $\mathrm{C}$ may be an effective treatment option for third-line chemotherapy in advanced colorectal cancer. Tumori 2006; 92: 384-8.

[16] SAIF MW, KALEY K, BRENNAN M, GARCON MC, RODRIGUEZ G. Mitomycin-C and capecitabine (MIXE) as salvage treatment in patients with refractory, metastatic colorectal cancer: a retrospective study. Anticancer Res 2013; 33: 2743-6.

[17] HOFHEINZ RD, HARTMANN JT, WILLER A, OESCHLE $\mathrm{K}$, HARTUNG $\mathrm{G}$ et al. Capecitabine in combination with mitomycin $\mathrm{C}$ in patients with gastrointestinal cancer: results of an extended multicentre phase-I trial. Br J Cancer 2004; 91: 834-8. http://dx.doi.org/10.1038/sj.bjc.6602025

[18] LIM DH, PARK YS, PARK BB, JI SH, LEE J et al. Mitomycin-C and capecitabine as third-line chemotherapy in patients with advanced colorectal cancer: a phase II study. Cancer Chemother Pharmacol 2005; 56: 10-4. http://dx.doi.org/10.1007/ s00280-004-0963-2

[19] KANG EJ, CHOI YJ, KIM JS, KIM ST, PARK KH et al. Mitomycin-C, 5-fluorouracil, and leucovorin as a salvage therapy in patients with metastatic colorectal adenocarcinoma. Asia Pac J Clin Oncol 2010; 6: 286-91. http://dx.doi.org/10.1111/j.17437563.2010.01334.x

[20] NIELSEN DL, PALSHOF JA, LARSEN FO, JENSEN BV, PFEIFFER P. A systematic review of salvage therapy to patients with metastatic colorectal cancer previously treated with fluorouracil, oxaliplatin and irinotecan $+/$ - targeted therapy. Cancer Treat Rev 2004; 40: 701-15. http://dx.doi. org/10.1016/j.ctrv.2014.02.006 